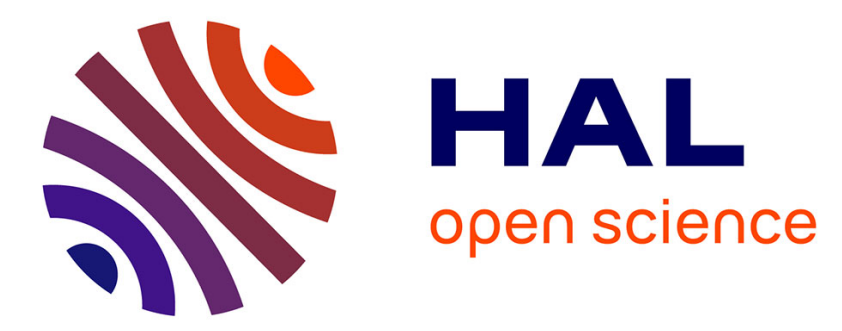

\title{
State of the art of plastic sorting and recycling: Feedback to vehicle design
}

Daniel Froelich, Elisabeth Maris, Nizar Haoues, Léonard Chemineau, H Renard, F. Abraham, R. Lassartesses

\section{- To cite this version:}

Daniel Froelich, Elisabeth Maris, Nizar Haoues, Léonard Chemineau, H Renard, et al.. State of the art of plastic sorting and recycling: Feedback to vehicle design. Minerals Engineering, 2007, 20, pp.902-912. 10.1016/j.mineng.2007.04.020 . hal-01026519

\section{HAL Id: hal-01026519 https://hal.science/hal-01026519}

Submitted on 4 Sep 2017

HAL is a multi-disciplinary open access archive for the deposit and dissemination of scientific research documents, whether they are published or not. The documents may come from teaching and research institutions in France or abroad, or from public or private research centers.
L'archive ouverte pluridisciplinaire HAL, est destinée au dépôt et à la diffusion de documents scientifiques de niveau recherche, publiés ou non, émanant des établissements d'enseignement et de recherche français ou étrangers, des laboratoires publics ou privés. 


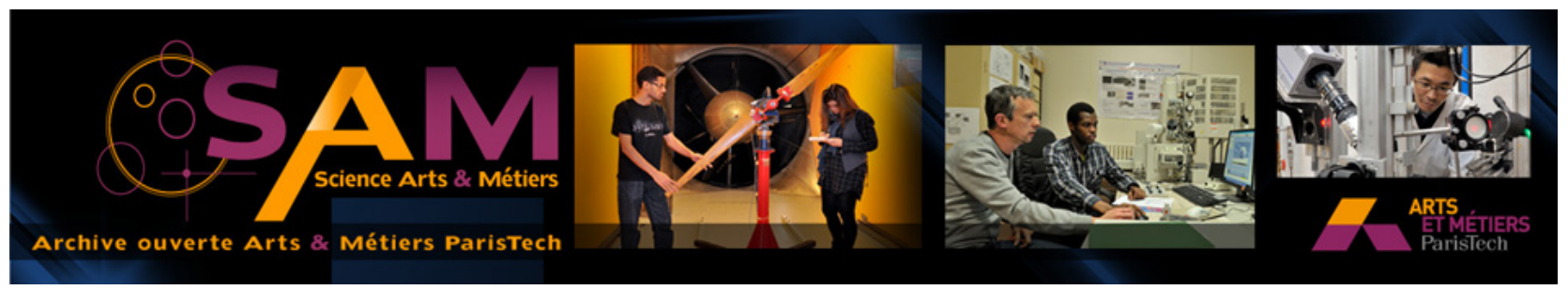

Science Arts \& Métiers (SAM)

is an open access repository that collects the work of Arts et Métiers ParisTech researchers and makes it freely available over the web where possible.

This is an author-deposited version published in: http://sam.ensam.eu

Handle ID: .http://hdl.handle.net/10985/8370

\section{To cite this version :}

Daniel FROELICH, Elisabeth MARIS, Nizar HAOUES, Léonard CHEMINEAU, H RENARD, F ABRAHAM, R LASSARTESSES - State of the art of plastic sorting and recycling : Feedback to vehicle design - Minerals Engineering n²0, p.902-912 - 2007 


\title{
State of the art of plastic sorting and recycling: Feedback to vehicle design
}

\author{
D. Froelich ${ }^{\mathrm{a}, *}$, E. Maris ${ }^{\mathrm{b}}$, N. Haoues ${ }^{\text {a }}$, L. Chemineau ${ }^{\text {a }}$, H. Renard ${ }^{\text {a }}$, \\ F. Abraham ${ }^{\mathrm{c}}$, R. Lassartesses ${ }^{\mathrm{c}}$ \\ ${ }^{a}$ Laboratoire Modélisation, Analyse et Prévention des Impacts Environnementaux, Ecole Nationale d'Arts et Métiers, \\ 4. Rue lac Majeur Savoie Technolac, 73375 Le Bourget du Lac Cedex, France \\ b Société d'Etudes et de Recherches de l'Ecole Nationale d'Arts et Métiers, 151, bd de l'Hôpital 75 013, Paris, France \\ ${ }^{\mathrm{c}}$ Renault Research Direction FR TCR LAB 1 13, Service 641000-Recycling Engineering, 1 Avenue du Golf, 78288 Guyancourt Cedex, France
}

\begin{abstract}
Today car manufacturers are beginning to integrate recycling constraints in the first stages of the design of a new car due to their concern regarding the effects of car design on the recovery of material after End-of-Life Vehicle treatment.

Improved understanding of the recycling process can help designers to avoid contaminants in the recycled product and improve the efficiency of current and new sorting methods. The main goal of this paper is to describe the state of the art of the technical efficiency of recovery channels for plastics in Europe in order to define requirements for automotive plastic part design.

This paper will first present the results of a survey on industrial and innovative recycling technologies mainly originating from the mining sector, and secondly a simplified methodology for car design integrating plastic recycling constraints.

This methodology concerns material association and compatibility, the type of assemblies favourable to better recycling, and better reuse of recycled products in cars.
\end{abstract}

Keywords: Recycling; Mining; Sorting method; Liberation; Modelling; Environmental

\section{Introduction}

Due to political reasons initially linked to the rarefaction of new landfills, the European Commission set up directive to manage the end of life of post consumer products (Directive 2000/53/EC). The particularity of this directive is continuous support for recycling. Thanks to this orientation concerning waste management, a real policy of raw resource management based on the recycling of end-of-life products has been defined.

Apart from the inevitable shortage in the long term of certain raw materials, major phenomena linked to the economic context such as the rapid development of certain

\footnotetext{
* Corresponding author.

E-mail address: daniel.froelich@chambery.ensam.fr (D. Froelich).
}

countries such as India and China have caused an increase in raw material demand and a relative shortage of oil but also of copper and special and rare metals.

End-of-life products are a secondary source of materials for all countries with high growth or countries, such as in Europe, with few mining resources, and have thus become a strategic economic stake for material producers.

End-of-life products can be considered as a new resource with a high energy content. However, it is generally difficult to recycle these materials because of their association with other materials which are incompatible with each other. Therefore, it is necessary to study disassembly, automated sorting and compatibility methods and to design goods in view of the constraints of the recycling industry. An end-of-life product such as an end-of-life vehicle represents more than a simple ore since it is the result of 


\section{Nomenclature}

ABS acrylonitrile-butadiene/styrene EPDM ethylene-propylene dimeres

$\mathrm{PC}+\mathrm{ABS}$ polycarbonat $+\mathrm{ABS}$ blend

PET polyethyleneterephthalate

PA 66 polyamide 66

PP copo, P/E polypropylene copolymer

PP-T20 polypropylene $+20 \%$ talc

PP-GF polypropylene + glass fibers

PP-E expanded PP
PE polyethylene

LDPE low density polyethylene

PMMA polymethylmethacrylate

$\mathrm{PPO}+\mathrm{PA}$ polyphenyleneoxide $+\mathrm{PA}$

PVC polyvinylchloride

POM polyoxymethylene

PUR reticulated polyurethane

TPO thermoplastic elastomer polyolefin

ELV end-of-life vehicle metallurgical, chemical and plastics transforming processes that created high added value. To produce vehicles from recycled material requires less energy than from virgin materials (see Fig. 1) (Weiss et al., 2000).

The automotive manufacturer Renault, who commissioned this research project, has directed its recycling strategy towards the use of recycled materials by introducing an increasing quantity of such materials in its cars over the past ten years. By creating demand in the market for recycled materials, Renault enhances the creation of the offer. This will facilitate the emergence of an increasingly industrial and technologically advanced recycling chain and the availability of high quality recycled materials which can be used for a larger number of automotive applications.

This approach was finalized by working on vehicle design for recycling, in particular on the subjects of plastic material diversity and the profits linked with polypropylene. This process of continuous improvement (see Fig. 2) set up by Renault and its recycling suppliers has lead to an increase in the use of recycled materials in technical products.

However, this successful strategy has reached its limits. The quantity of recycled plastic materials on the market is no longer sufficient to satisfy the needs of the automotive industry. For example, Renault estimates that its own need of recycled polypropylene is about 100,000 tons per year, whereas the current supply in Europe corresponding to the specifications of all the automakers does not exceed 180,000 tons per year.

This gap is due to:

- The differences between the polypropylene composition from a vehicle which was just produced and that of an end-of-life vehicle produced 15.4 years ago on average in France.

- The gap between the complexity of current end-of-life products and available sorting and recycling techniques.

Currently, it has been estimated that only $3 \%$ or $4 \%$ of the plastics contained in end-of-life vehicles are really recycled. The design for recycling of plastic equipment is not in phase with the technical realities of sorting and recycling processes.

In order to continue the development of this industry, it is necessary to focus on the following objectives:

- To develop advanced sorting techniques to deal with complex associations of different plastics, adhesives and plastic or metallic inserts. This is the case of bumpers, panel instruments, seats, door panels, and parts under the engine.

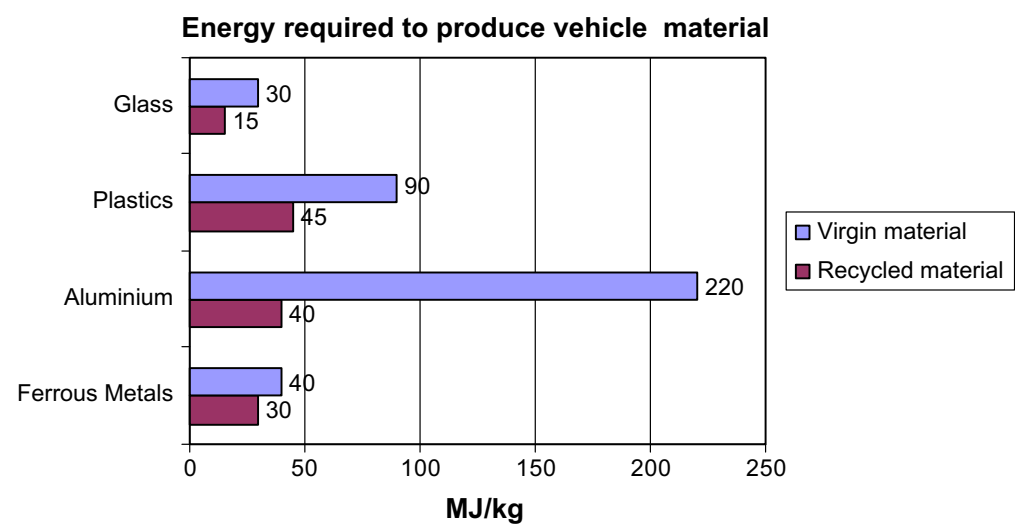

Fig. 1. Energy required for the production of an automotive vehicle for materials with the most environmental impacts (per kg), data taken to table 1.2 , page 10 (Weiss et al., 2000). 


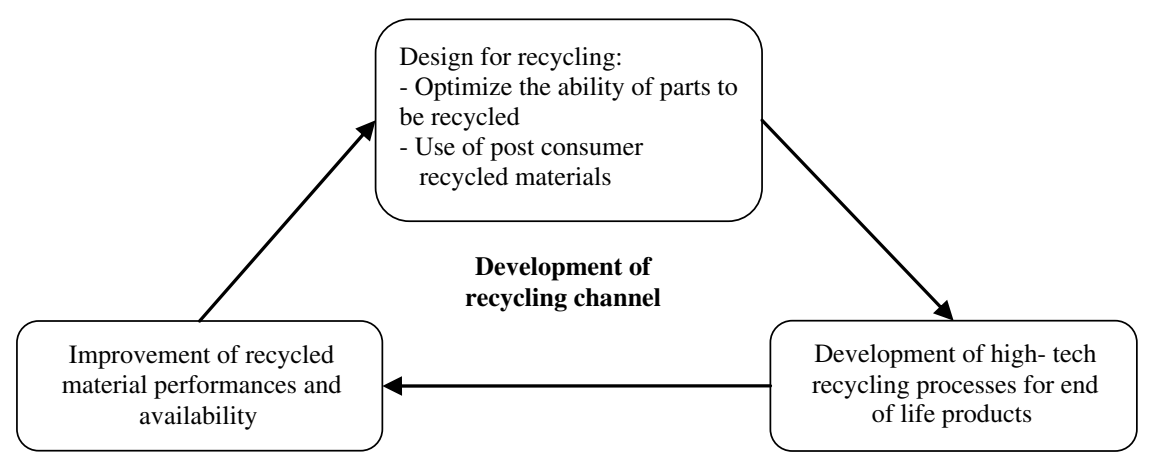

Fig. 2. Renault's recycling virtuous circle of continuous improvement.

- To define design rules in adequacy with the technological limits of the sorting processes existing in the recycling industry.

\section{Objectives}

There are already several studies dealing with the modelling of recycling process limits (Froelich, 2000; Mathieux et al., 2001a,b; Reuter et al., 2006), with disassembly methods (Ferrao and Amaral, 2006; Haoues et al., 2004) and with the Life Cycle Analysis and the consequences on the design stage (Mathieux et al., 2006).

The originality of our approach consists in creating a tool based on recycling process performances which makes it possible to choose materials by integrating the separation ability of the current recycling routes, the compatibility of mixed plastics association and the quality of the secondary material product. Data on the performances of existing sorting and recycling routes was collected and analysed in order to define the minimum requirements to take into account in the first stage of plastic part design for a new car project.

This study essentially concerns polypropylene due to its use in several applications in the vehicle industry and other industries. Moreover, its presence is important in massive parts such as bumpers, instrument panels, interior trim, wheel passage, tanks, etc. This method can be also developed for other polymer matrixes.

The first objective of this study was to define a typology of polypropylene parts produced by the automotive industry in terms of material associations, assembly and coating.

The second objective was to draw up a summary of automated sorting process performances at the industrial and laboratory levels based on a survey and to determine the limits of automated sorting and material recycling for the car parts defined previously.

The third objective was to acquire basic knowledge concerning the compatibility of polypropylene with the presence of polymer impurities. This compatibility was translated by taking as criteria the losses of mechanical properties and the aspect of recycled materials with impurities, the conditions of recycling being those of an effective recycler $(\mathrm{C} 2 \mathrm{P}, \mathrm{GP})$. This definition of the compatibility related to the process of recycling is thus separated from the concept of chemical compatibility close to the thermodynamics approach. A bibliographical study coupled with laboratory tests made it possible to draw up a first specification sheet (or requirement) for plastic compatibility.

The fourth objective was to define design constraints in view of recycling. The final result was the development of a tool for plastic part design.

The geographic area of this study was Europe plus the United States. Nearly 300 recyclers were contacted in 2002 (updated in 2004) for an exploratory survey 43 gave reliable data and 9 companies - the most interesting ones for the recycling of PP - were then visited for a detailed investigation.

\section{Definition of the typology of a polypropylene automotive part}

In order to determine the limits of recycling, a part typology was defined from the different designs of polypropylene automotive parts. It included most of the possibilities of contaminants, coatings and assemblies found in automotive applications such as the bumper, console, dashboard, door panel, fender, front seat, fuel tank, hatch panel, radiator grille, rear floor, rear light, side protection.

The following figure (Fig. 3) resumes all the main typologies that can be taken into account.

The numbers in Fig. 3 correspond to the following typology:

Number 1: the part is made of PP, the main polymer. The contaminant can be:

Number 2: a coating of paint, film, different kinds of skin, foam, carpet, joint, chromium plating, aluminium plating and glue.

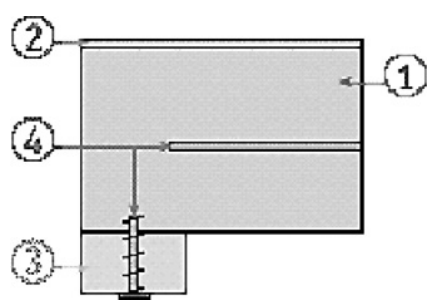

Fig. 3. Part typology. 
Number 3: sub part made of other materials (ABS, POM,...).

Number 4: different kinds of links or inserts, made of metal or plastics.

This typical part was attached to a questionnaire to illustrate the different types of parts; recyclers will have to recycle them in the near future to reach the objectives of the European directive.

\section{Methodology of investigation and assessment of recycling network performances}

An investigation was conducted in Europe and the US in order to identify producers of recycled PP, sorting technologies used by recycling companies, and the performance and limits of processes, in order to define design rules.

\subsection{Methodology of investigation}

In a first phase, an exploratory questionnaire was sent to 293 companies and in a second phase a detailed questionnaire was filled out with the selected companies. From the exploratory questionnaire, 43 answers were reliable; this gave a profile of recycling companies.

Then nine companies working specifically on PP sorting were visited to answer a detailed questionnaire. From this questionnaire, data on performance of automated sorting process was collected. Performance determines the recycling limits for the typical car part defined previously and defines design rules.

\subsection{Current technological know-how of European recyclers}

As shown in the previous figure (Fig. 3), an automobile part is a complex mixture of materials and coatings which have to be separated before recycling.

Recycling activities have some similarities with mining activities:

- Mixtures are complex. The valuable material has to be extracted from the residue.

- The profitability of plastic can be achieved only with mass production due to the relatively low cost of virgin polypropylene.

- Low-cost sorting processes are required.

This explains why most of the technologies for waste sorting, especially for plastics, are derived from proved mining technologies, and why European mining companies have integrated waste recycling activities, for instance Metal Europe in France and Kali und Salz in Germany.

Recycling industries are quite similar to mining activities. For example mixtures are complex, but it should be realised that the ores from post-consumer products are much more complex than traditional mineral ores. How- ever, the differences make the understanding and performance of consumer recycling processes even more difficult complex than in the case of mineral processes (Reuter et al., 2005).

In Europe, recyclers' technologies mainly include:

- Shredding and grinding for material liberation.

- Mass gravimetric separation (heavy medium, flotation).

- Aerodynamic separation.

- Electrostatic or triboelectric separation.

- Eddy current.

- Magnetic separation.

Certain specific sorting technologies have been developed for plastics such as optical automated sorters and chemical dissolution.

The optical sorter technologies are used mostly for plastic waste from bottles (and the food sector) and are essential to detect different colours with colour sorters, or different plastic grades with near infrared spectrometry. However, today it is still impossible to discriminate different families of black plastics with automated infrared sorters, yet they are the main plastics in car parts.

Chemical dissolution technologies are not cost-effective for commodity polymers but are sometimes the only solution for the liberation of different coatings associated with polypropylene, such as paint or skin.

Fig. 4 shows the technologies used by the recyclers who were contacted. The data come from the reliable answers to an exploratory questionnaire sent back by 43 European companies out of a total number of 293 companies.

The reliability of the answers was first determined by checking the information through phone contacts or company visits, and the information was also compared with databases on company activities such as Kompass. Secondly only completely filled questionnaires were considered reliable.

It was noted that a large amount of recyclers use sorting technologies. The reason is quite clear: easy-to-recycle sources of plastics from waste are now treated and recyclers are looking for more complex sources of material such as part production waste or end-of-life parts from vehicle dismantling or from garages (generally batteries, bumpers, interior trim) or waste flows from packaging.

Some recyclers are now extracting a few families of plastics from automotive or electronic shredder residues.

In this case they have developed sophisticated process chains in order to liberate the different materials of a part and recycle them.

\section{Example for bumper recycling.}

In the survey, bumper recycling processes are a representative example of technologies used for the recycling of end-of-life plastic parts. In Europe, bumpers are mainly made of polypropylene but contain metal inserts (Iron, Aluminium) which can damage the cutter, PVC, SMC or PE which are not compatible with PP and must be sorted, and paint, which must be removed, in order to recycle the 


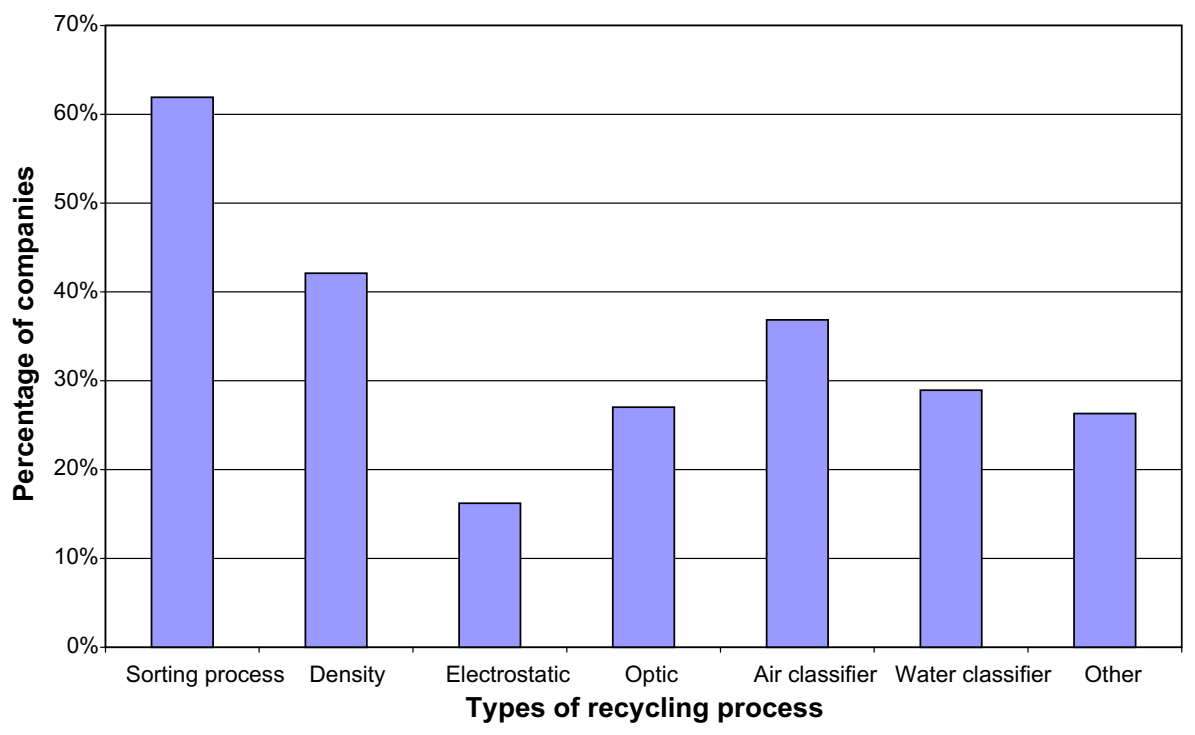

Fig. 4. Types of process used by contacted companies.
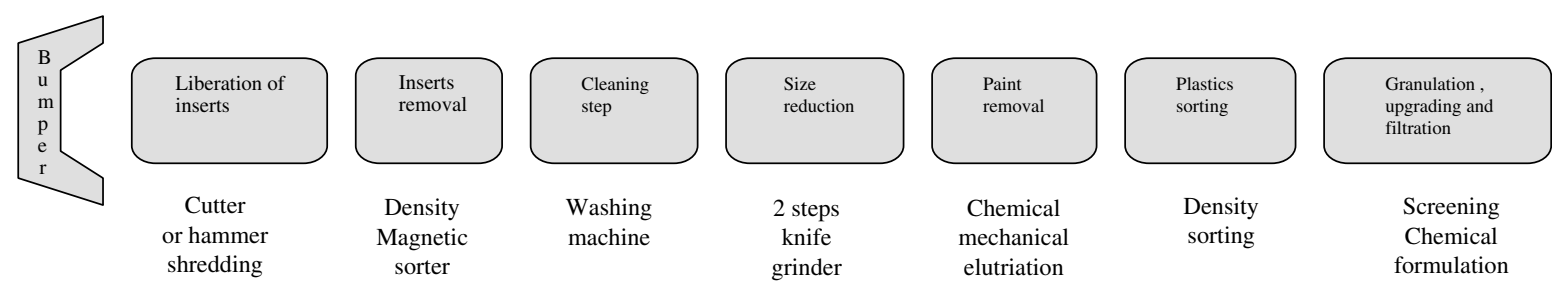

Fig. 5. Processes steps and technologies used to recycle bumper.

materials with a high value. Recyclers have developed the following process steps (see Fig. 5).

Depending on the recycler's technology, shock absorbers made of PE and SMC have to be hand sorted because these materials are not chemically compatible with PP. This manual removal of these contaminants must be considered as a technological and economical limit of the process, to be taken into account in the design of new bumpers to enhance recycling.

\subsection{Typology of companies}

In order to answer the question of how to increase plastics production, links were made between the size and the sorting activities of companies. Many small companies with a production capacity below 10,000 tons per month are generally situated close to the area of plastic waste production. They are ready to develop sorting processes to improve quality but today they are not paid enough for quality products and the Asian market is much more attractive.

The main activity of larger companies with a production of over 10,000 tons per month is the production of granulates. To sell good quality granulates, these companies need to firstly improve their knowledge of polymer chemistry for example the compatibility of two grades of polyolefin is not obvious, due to their difference in viscosity - and secondly to secure, in time and quality, their incoming plastic supply.

Among the sample of our surveys, two countries have very similar features, Germany and the Netherlands (see Table 1). In these countries entire companies sell granulates and seventy percent have a production over 10,000 tons. Around $50 \%$ of these companies with a production over 10,000 tons per year use at least one sorting process. But for companies with a production below 10,000 tons, the

Table 1

Sample of company production in Germany, the Netherlands and the UK

\begin{tabular}{|c|c|c|c|c|c|c|c|c|}
\hline \multirow[t]{2}{*}{ Country } & \multirow{2}{*}{$\begin{array}{l}\text { Answers } \\
\text { Numbers }\end{array}$} & \multicolumn{5}{|c|}{ Companies total production } & \multicolumn{2}{|l|}{ PP production } \\
\hline & & Tons & $\geqslant 10,000 \mathrm{~T}(\%)$ & $\geqslant 10,000 \mathrm{~T}+$ sorting $(\%)$ & $<10,000 \mathrm{~T}$ & $<10,000 \mathrm{~T}+$ sorting & Percentage $(\%)$ & Tons \\
\hline Germany & 13 & $1,59,500$ & 77 & 46 & 23 & 8 & 77 & 72,971 \\
\hline UK & 7 & 50,000 & 33 & 17 & 67 & 50 & 29 & 22,300 \\
\hline
\end{tabular}


Table 2

Development level classification

\begin{tabular}{lll}
\hline Ability to be sort & Colour code & Scope of validity \\
\hline Easy & Green & $\begin{array}{l}\text { At least three industrial operations } \\
\text { exist }\end{array}$ \\
$\begin{array}{l}\text { Difficult } \\
\text { Very difficult }\end{array}$ & $\begin{array}{l}\text { Dark blue } \\
\text { Red }\end{array}$ & $\begin{array}{l}\text { Only two industrial operations exist } \\
\text { Only one industrial operation or } \\
\text { sale facilities or pilot exists } \\
\text { No industrial operation or sale } \\
\text { Impossible }\end{array}$ \\
facilities or pilot exist \\
Not known & Blue & No answer from the companies \\
\hline
\end{tabular}

profile of the sample is quite different and depends on the country. In the UK, most companies produce $<10,000$ tons per year. The context of the country is also a parameter to take into account to improve the quality and cost effectiveness of plastics recycling.

Because most of the European recycling companies are small and medium-sized companies with a production of around 10,000 tons per year of recycled plastics from production scrap and from pre-sorted end-of-life plastic parts, these companies are generally too small to guarantee material quantity and quality to automotive producers. They are generally limited to supplying secondary applications which do not require technical grades.

For a mature industrial sector in the future, recycling activities may be managed by three other kinds of companies in order to respond to manufacturers' demand:

\section{- Plastic producers}

Virgin plastic producers have a strong political and economical interest in properly managing the outcome of end-of-life plastics. Recycling could be an extension of their plastic material supply activity. They are experts in plastic chemistry and have launched research programmes and patents to produce high quality recycled plastics.However, they are not able to control the endof-life plastic flows and have not developed the technology to sort and extract the selected plastic they are interested in, with a level of purity allowing it to be used as a raw material in a profitable way. A few European plastic companies working in recycling have limited their activity to the recycling of their own production scrap or that of their customer.

\section{- Plastic transformers}

Plastic transformers could find it advantageous to become recycling operators. They have excellent knowhow in plastic transformation and compounding which can be relevant for plastic recycling. From a political point of view, they also have a shared responsibility in the outcome of their parts. The application of the European directive could be an opportunity to reduce their production costs through the use of recycled plastics. However, they also have no control over end-of-life plastic flows.

- Large waste collectors

Large waste collection companies in charge of packaging collection and recycling, product dismantling and

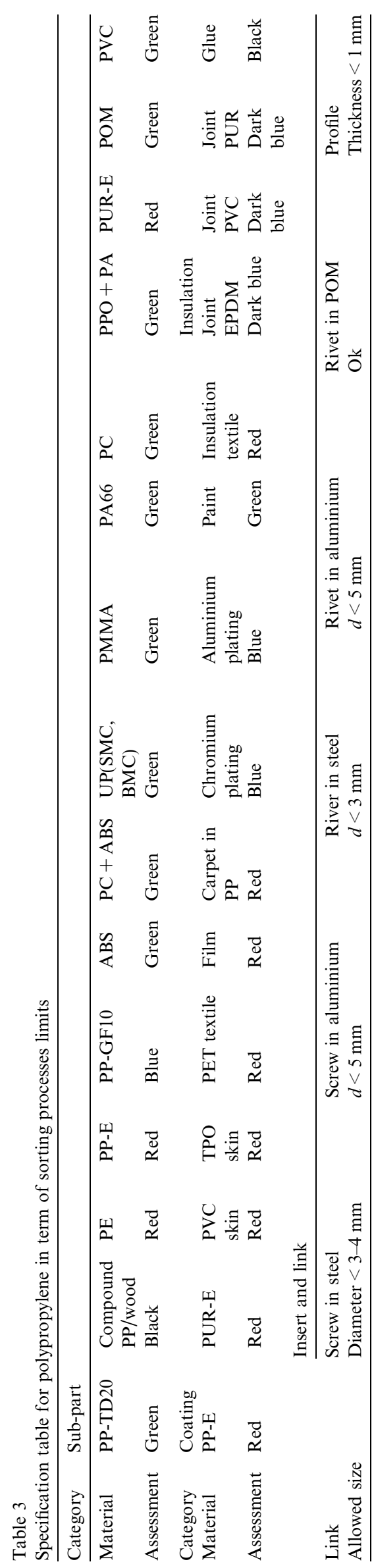


shredding generally manage a large amount of plastic waste. On one hand, landfill and incineration are becoming limited and expensive. On the other hand, the market no longer meets the manufacturers' demand and the value of plastic waste is increasing. In this case, the market for recycled material could be driven by the availability of plastic waste, which gives waste companies an opportunity to play an important role in the recycling business.

\subsection{Limits of the sorting processes of the existing European operators}

In order to protect the know-how of the recyclers, the questionnaire was focused on material sorting efficiency. The result did not provide an accurate vision of how the mixture is sorted, but focused on the sorting efficiency of the chain used to treat and sort the material of the typical part.

From the information received from all the recycling companies concerning their ability to sort contaminants, presented by part typology (see Fig. 3) in a questionnaire, a classification was made with four levels in the following table (see Table 2); The results were integrated into a specification sheet for polypropylene (see Table 3).

\section{Compatibility regarding recycling: management of impurities}

Due to the fact that sorting processes do not have a $100 \%$ sorting efficiency, their performances are evaluated by a refusal rate (non recovery) and a rate of impurities included in the final material. This impurity rate is prejudicial to the quality. It is then necessary to study the compatibility of the main material with the impurities present.

The compatibility of polypropylene with one kind of impurity is evaluated by three levels of outlets, noble, cascade and low grade, depending on the loss of properties.

\subsection{Compatibility from a recycling point of view}

Two different polymers, whose mixture constitutes a material with satisfactory properties, with respect to the values in Table 4, are described as compatible with outlets or applications.

There are two main causes for the loss of properties of binary mixed plastics:

- Chemical incompatibility: the material resulting from the plasticization of two polymers has physical properties inferior to those of one of its components.

- An incompatibility associated with the plastics' processing, particularly their processing temperature. For binary mixtures, the highest processing temperature of the two polymers is chosen, but it can damage the polymer with the lower processing temperature, leading to a low grade quality of the mixture.
Table 4

Assessment criteria for property loss

\begin{tabular}{|c|c|c|}
\hline Function & Application & Mechanical and surface property \\
\hline Noble & $\begin{array}{l}\text { Car } \\
\text { application }\end{array}$ & $\begin{array}{l}\text { Mechanical loss of property }<5 \% \\
\text { and } n \text { visible surface alteration }\end{array}$ \\
\hline Cascade & $\begin{array}{l}\text { Not car } \\
\text { application }\end{array}$ & $\begin{array}{l}\text { Mechanical loss of property }<20 \% \\
\text { or small surface alteration }\end{array}$ \\
\hline $\begin{array}{l}\text { Low } \\
\text { grade }\end{array}$ & $\begin{array}{l}\text { Degraded } \\
\text { application }\end{array}$ & $\begin{array}{l}\text { Mechanical loss of property up to } \\
20 \% \text { or strong surface alteration }\end{array}$ \\
\hline
\end{tabular}

\subsubsection{Definition of criteria to determine recommendations in terms of compatibility}

Table 4 was elaborated in order to define "noble, cascade and low grade" notions. These notions depend on criteria concerning the property losses of three polymers (PP, PP-10\% filled, and PP copo) in the presence of impurities. The properties considered are tensile strength, tensile strain, tensile modulus, flexural modulus, melt flow index, izod impact at $23{ }^{\circ} \mathrm{C}$ and $-18{ }^{\circ} \mathrm{C}$, and aspect.

Binary mixtures were considered.

\subsubsection{Data sources for specifications concerning plastics compatibility}

The data concerning compatibility come from bibliographical sources, contacts with chemists and recyclers, and laboratory tests performed by Chiarilli (ChiarilliSabin, 1996) and ENSAM.

To draw up a summary specification table on plastics compatibility, different types of data were gathered:

- Processing conditions during extrusion.

- Choice of extrusion temperature.

- Type of mechanical properties considered.

For the Bayer table (Bayer, 2000) and the other chemists, It was not possible to determine the first and the third data. The extrusion temperature of a binary mixture is that of the polymer which has the highest temperature. The effect on properties is miscibility or not.

For recycling companies the extrusion temperature is that of the polymer present in the highest quantities. In this case the polymer impurity affects the main polymer in another way. Its action is closer to that of a filler if the extrusion temperature is below that of the impurity, and degradation of the polymer impurity can occur if it is the opposite.

Concerning the tests performed by Renault (ChiarilliSabin, 1996), the conditions are well known and the extrusion temperature chosen is the same one as for the chemists.

However, the extrusion temperature chosen for the ENSAM tests was the one adopted by two recycling companies, i.e. the temperature of the main material.

In a first phase, it appeared that data concerning polymer compatibility exist for PP, but these data are at the same time divergent for certain mixtures of polymers and 
Table 5

Simplified PP compatibility table for recycling

\begin{tabular}{|c|c|c|c|c|c|c|c|c|c|c|c|c|c|c|}
\hline Materials & Function & PP-T20à40 & PP-E & $\begin{array}{l}\text { Compound } \\
\text { PP/wood }\end{array}$ & LDPE & $\mathrm{ABS}$ & $\mathrm{ABS} / \mathrm{PC}$ & PMMA & PA 66 & PC & PUR-E & PET & POM & PVC \\
\hline \multirow{3}{*}{$\begin{array}{l}\text { Outlet/tolerated } \\
\text { mass } \% \text { of } \\
\text { impurities } \\
\text { for PP }\end{array}$} & Noble & $\mathrm{Uk}$ & $<3 \%$ & Uk & $0.1-5 \%$ & $0.1 \%$ & $0.1 \%$ & Uk & & Uk & $0 \%$ & $<3 \%$ & Uk & Uk \\
\hline & Cascade & $\mathrm{Uk}$ & Uk & $\mathrm{Uk}$ & $\mathrm{Uk}$ & $1.5 \%$ & $1.5 \%$ & Uk & $2-4 \%$ & $<3 \%$ & $0 \%$ & Uk & $2-4 \%$ & $<3 \%$ \\
\hline & Low grade & $\mathrm{Uk}$ & $\mathrm{Uk}$ & $\mathrm{Uk}$ & $10 \%$ & $3 \%$ & $3 \%$ & $3 \%$ & $6.0 \%$ & $\mathrm{Uk}$ & $0 \%$ & $\mathrm{Uk}$ & $6 \%$ & $\mathrm{Uk}$ \\
\hline
\end{tabular}

Unknown.

not really adapted in this case to the specifications of automakers. Data concerning filled PP are inexistent.

Differences between compatibility tables drawn up by chemists like Bayer, Dow Plastics, GEP and the tables used as a decision-making support tool by manufacturers of electronic and automotive products (Chrysler, Ford, etc.) were also observed. Exact quantitative data concerning several minor materials when mixed together was not known; this was the case for compatible expanded materials, paints, chromium materials (such as logos made of chromium plated ABS), thermoplastics containing natural fibres and TPO.

Compatibility tests were performed by a polypropylene recycler in order to procure certain information that was still lacking after the bibliographical search and contacts with chemists and recycling companies.

\subsubsection{Results: specification table for PP in terms of compatibility}

The following table (Table 5) presents specifications for PP part design according to the definition of compatibility from the recycling standpoint presented previously. Depending on the rate and the type of polymer impurity, three outlets are possible for recycled PP from car parts: noble, cascade or degraded. This table integrated the limits of recycling processes.

\section{Summary of sorting and compatibility constraints}

Out of the companies visited, nine of them sorted PP. This material is easily recyclable in comparison with other plastics.

Four kinds of materials associated with PP are problematic at an industrial sorting level:

- PE;

- Polyurethane foams;

- Expanded PP;

- Coatings.

Moreover, problems of chemical compatibility were observed (particularly LDPE, PUR and PVC coatings) or problems with processing plastics, such as expanded PP for example, when these materials are not well extracted from the PP.
The result summary shows that an impurity rate in polypropylene $>3 \%$ leads to outlets with degraded functions, i.e. one of the PP properties was reduced by about $20 \%$. In order to have noble outlets, i.e. with a property loss $<5 \%$, the impurity rate during the sorting process must be $<3 \%$. The compatibility additives represent an extra cost for recyclers and are generally not used, aside from antioxidants.

\section{Feedback to design}

\subsection{Renault's tool for designers}

Renault translated and simplified the information contained in specification tables for sorting process limits and material compatibilities (Tables 3 and 5) into a guide for their designers. An example of a specification sheet for car designers is presented in the following figure (Fig. 6).

\subsection{Case study}

Case study of a Renault bumper which was designed in order to integrate recycling constraints:

Front bumper, total mass $=6.81 \mathrm{~kg}$ (see Table 6).

- Main materials: main materials mass, $M=6.3 \mathrm{~kg}$ which represents $92 \%$ of the total mass.

- PP, P/E.

- PP $10 \%$ filled.

- Minor materials:

- Expanded PP (3\%).

- PP 28\% TD filled (1.3\%).

- Chromium plated ABS $(0.2 \%)$.

Materials can be chosen by considering the data of the design-for-recycling specification sheet. An example of a specification sheet for Renault is presented in the next figure (Fig. 6). An assessment of a car part is presented in the following table (see Table 6).

The polypropylene bumper shield represents the main material and can be accepted in a recycling chain using automated sorting processes, but it is necessary to dismantle the fog lamps. 


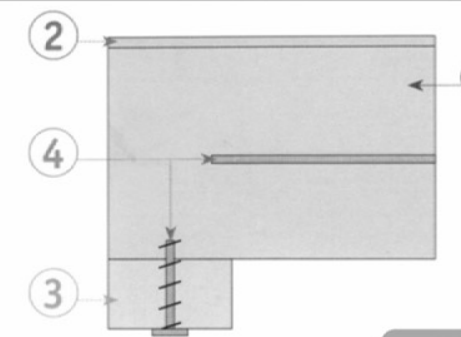

(2)

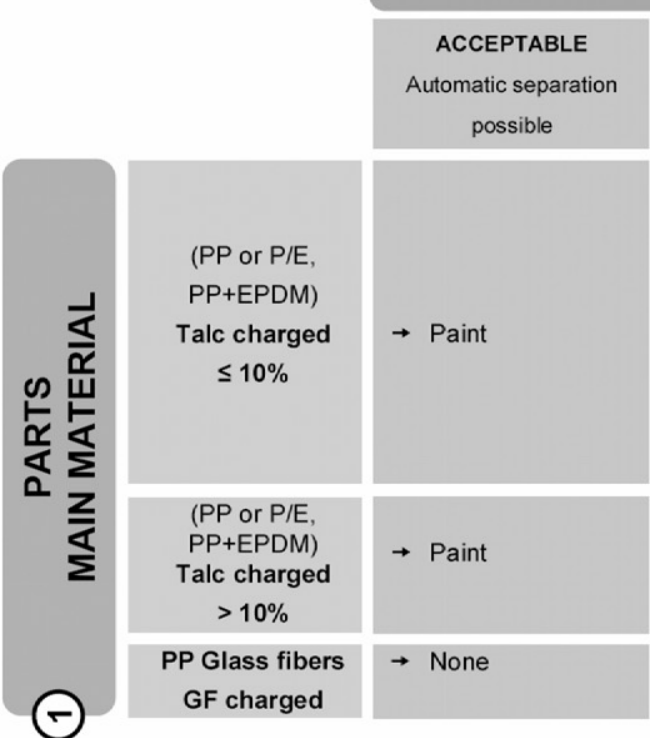

\section{ASSUMPTIONS :}

$>$ Parts whose main material is PP (1) are dismantled and shredded.

The PP material will be recycled and will be used to manufacture new parts.

$>$ Attached elements (3), inserts and fitting elements (4) are sorted by density separation.

>PP parts covered by prohibited coatings (2) can not be recycled, these parts are directly sent in landfill or are incinerated.

\section{COATINGS}

|

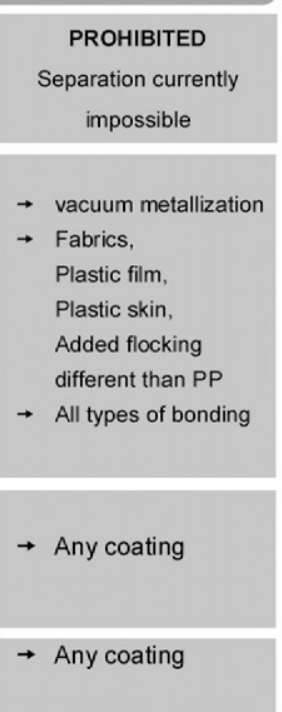

\section{(3) ATTACHED ELEMENTS}

\begin{tabular}{|c|c|}
\hline $\begin{array}{l}\text { ACCEPTABLE } \\
\text { Automatic sorting } \\
\text { possible }\end{array}$ & $\begin{array}{c}\text { MANUAL } \\
\text { DISMANTLING } \\
\text { NECESSARY }\end{array}$ \\
\hline $\begin{array}{ll}\rightarrow & \text { ABS } \\
\rightarrow & \text { ABS/PC } \\
\rightarrow & \text { SMC } \\
\rightarrow & \text { PMMA } \\
\rightarrow & \text { PA66 } \\
\rightarrow & \text { PC } \\
\rightarrow & P O M \\
\rightarrow & P P>20 \% \text { talc } \\
\rightarrow & P P>10 \% \text { GF }\end{array}$ & $\begin{aligned} \rightarrow & \text { PE } \\
\rightarrow & \text { PP-E } \\
\rightarrow & \text { PUR-E } \\
\rightarrow & \text { Natural fibers } \\
& \text { inserted in PP } \\
& \text { (linen, cotton, } \\
& \text { woodstock) }\end{aligned}$ \\
\hline $\begin{aligned} \rightarrow & \text { PP family, P/E } \ldots \\
& <10 \% \text { talc }\end{aligned}$ & $\rightarrow$ Any plastic \\
\hline$\rightarrow \begin{array}{l}\mathrm{PP} \text { family }<10 \% \\
\text { talc }\end{array}$ & $\rightarrow$ Any plastic \\
\hline
\end{tabular}

(4) INSERTS \& FITTING ELEMENTS

\section{ACCEPTABLE}

automatic separation possible

$\rightarrow$ Steel screws and rivets whose diameters are lower than $4 \mathrm{~mm}$

$\rightarrow$ Aluminium screws and rivets whose

diameters are lower than $5 \mathrm{~mm}$

$\rightarrow$ POM rivets

$\rightarrow$ Small metal sections whose thickness is lower than $1 \mathrm{~mm}$

$\rightarrow$ For any other case : manual dismantling is necessary

Source : ENSAM study : "End of Life Vehicle recycling paths", july 2002, updated in 2004

EXAMPLE :

$>\mathrm{A}$ trim part whose the main material is PP charged with $10 \%$ talc can have ABS/PC components, can be painted and can have POM rivets and metallic fasteners whose thickness is lower than $1 \mathrm{~mm}$, but it must not contain material flocking as PET...

Fig. 6. Example of specification sheet used by Renault designers. 


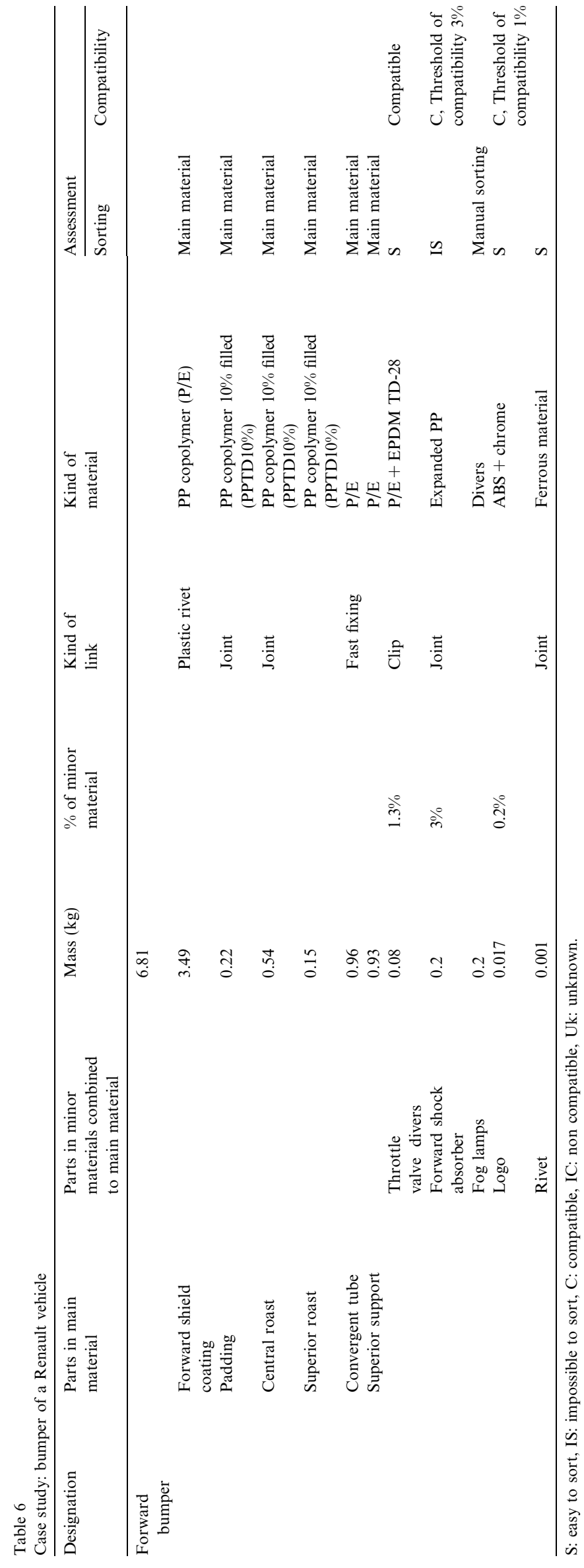

The other parts associated with the shield that cannot be sorted at an industrial level, such as PP 10\% talc filler, are perfectly compatible because the properties of the main material are preserved. The outlets are noble.

It is impossible to extract the expanded polypropylene shock absorber from the main material and there is no data about compatibility regarding industrial recycling (i.e. chemical and processing issues). Recent tests were performed on the chemical and processing compatibility of expanded PP that indicate that it is compatible chemically and at the level of its processing with PP when it does not exceed a rate of $3 \%$.

Logos made of chromium-plated ABS can be easily sorted out with industrial processes.

Ferrous metal rivets of weak sections are accepted in the recycling chain because they can be sorted out during the milling stage.

\section{Conclusion}

The results of the study indicate that automated sorting techniques come essentially from the techniques used in mines such as gravity separation, water or air classifiers, electrostatic sorting, differential crushing, flotation with foam, etc. These techniques are cost-effective and still in development to improve liberation rates, outputs, and the purity rate of end-of-life recycled products. However, more specific techniques concerning polymer properties are not well developed, particularly the technique related to the concentration of plastic fractions included in a product as well as the technique concerning plastics sorting.

It is clear that the existing technologies are not able to ensure the recycling of all the plastic materials of a vehicle and ensure the best value for these recycled materials.

Therefore, to implement the European directive, automotive designers must integrate rules for the development of plastics in compliance with the limits of the present recycling technologies.

Renault set up this first version of the design tool based on the survey of European recyclers' technologies. This tool was used by Renault and its suppliers for the latest generation of vehicle, which will make the recycling of these vehicles more realistic within fifteen years.

\section{References}

Bayer, 2000. Recycling and Design, Recommendations for Design and Production, Application Technology Information. <http://techcenter.lanxess.com/lup/emea/en/docguard/A0305.pdf?docId=1049>.

Chiarilli-Sabin, V., 1996. Analyse de seuils d'endommagement de mélanges de polymères incompatibles dans un objectif de recyclage, $\mathrm{PhD}$ thesis, Ecole des Mines de Douai.

Directive, 2000/53/EC of the European Parliament and the council of 18 September 2000 on end of life vehicles, official journal of the European communities, 21.10.2000.

Ferrao, P., Amaral, J., 2006. Design for recycling in the automobile industry: new approaches and new tool. Journal of Engineering Design 17 (5), 447-462, October 2006. 
Froelich, D., 2000. Towards ecological product design | [Vers l'eco-conception des produits] REE, Revue de L'Electricite et de L'Electronique 4, pp. 48-XIII.

Haoues, N., Froelich, D., Zwolinski, P., 2004. Disassembly for valorization in conceptual design. In: Proceedings of the SPIE - The International Society for Optical Engineering, vol. 5583, pp. 31-42.

Mathieux, F., Froelich D., Moszkowicz, P., 2001a. Development of recovery indicators to be used during product design process: method, potentialities and limits. In: Proceedings of the EcoDesign $2001-$ Second International Symposium on Environmentally Conscious Design and Inverse Manufacturing 2001, IEEE, Tokyo, Japan, 1115 December 2001, pp. 281-286.

Mathieux, F., Rebitzer, G., Ferrendier, S., Simon, M., Froelich, D., 2001b. Ecodesign in the European electr(on)ics industry - an analysis of the current practices based on case studies. Journal of Sustainable Product Design 1 (4), 233-245, Kluwer Academic Publishers.
Mathieux, F., Froelich, D., Moszkowicz, P., 2006. ReSICLED: a new recovery-conscious design method for complex products based on a multicriteria assessment of the recoverability. Journal of Cleaner Production. doi:10.1016/j.jclepro.2006.07.02.

Reuter, M.A., Van Schaik, A., Ignatenko, O., De Haan, G.J., 2006. Fundamental limits for the recycling of end-of-life vehicles, mineral engineering. Elsevier.

Reuter, M.A., Heiskanen, K., Boin, U.M.J., van Schaik, A., Verhoef, E.V., Yang, Y., Georgialli, G., 2005. The Metrics of Material and Metal Ecology. Elsevier Science, Amsterdam, ISBN 978-0-44451137-9, p. 706.

Weiss, M.A., Heywood, J.B., Drake, E.M., Schafer, A., Au Yeung, F.F., 2000. On the road 2020, a well-to-wheels assessment on new passenger car technologies. Report no. EL00-003, MIT Energy Laboratory, Cambridge, MA. 